\title{
Prioridades locais e sua relação com o desenvolvimento regional no Codemi de Ijuí
}

\section{Local priorities and its relationship with regional development in the Codemi from Ijuí}

Vinicios Gonchoroski de Oliveira - Doutorando em Desenvolvimento Regional pela Universidade de Santa Cruz do Sul/UNISC. Mestre em Desenvolvimento pela UNIJUÍ. E-mail: viniciosgdoliveira@gmail.com.

Rogério Leandro Lima da Silveira - Doutor e mestre em Geografia Humana pela Universidade Federal de Santa Catarina. Professor titular e pesquisador do Departamento de História e Geografia, e do Programa de Pós-Graduação em Desenvolvimento Regional da Universidade de Santa Cruz do Sul/UNISC. E-mail: rlls@unisc.br

\section{Resumo}

A democracia participativa/deliberativa introduz no debate sobre participação e democracia, distintos matizes de valorização da participação dos cidadãos nos processos circunscritos ao empoderamento e às tomadas de decisão, seus efeitos sobre o coletivo e para o regiões. Posto isto, procurou-se identificar, se os projetos prioritários eleitos por meio da participação da população na etapa municipal do processo de votação da Consulta Popular (CP) 2016-2017 dialoga com a perspectiva do desenvolvimento regional. O estudo é qualitativo, bibliográfico e documental, onde se analisou o Regimento Interno do Codemi, a ata com os resultados das demandas eleitas e o caderno de diretrizes da CP, comparandoos com o resultado da votação do CoredeNorc. Os principais resultados apontam para uma realidade desconexa com a compreensão de desenvolvimento adotada pelos estudos de desenvolvimento regional. Contudo, isto não torna o processo ilegítimo e desnecessário, pelo contrário, evidencia-se o desafio de se pensar uma agenda de desenvolvimento regional.

\section{Palavras-chave}

Democracia. Participação. Consulta Popular. Desenvolvimento Regional.

\begin{abstract}
Participatory / deliberative democracy introduces in the debate on participation and democracy, different nuances of valorization of citizen participation in processes limited to empowerment and decision-making, their effects on the collective and the development of the regions. Having said this, it was sought to identify whether the priority projects elected through the participation of the population in the municipal stage of the voting process of the Consulta Popular (CP) 2016-2017 dialogue with the regional development perspective. The study is qualitative, bibliographical and documentary, in which the Internal Regulation of Codemi was analyzed, the minutes with the results of the elect demands and the notebook of guidelines of the $\mathrm{CP}$, comparing them with the result of the Corede-Norc voting. The main results point to a disconnected reality with the understanding adopted in the regional development study. However, this does not make the process illegitimate and unnecessary, on the contrary, the challenge of thinking about a regional development agenda is evident.
\end{abstract}

\section{Keywords}

Democracy. Participation. Consulta Popular. Regional Development. 


\section{INTRODUÇÃO}

A configuração político-administrativa do Estado $^{1}$ brasileiro, após o processo de redemocratização de 1988, culminou na elaboração de um dos mais importantes documentos de garantia de direitos, deveres e liberdades de cidadãos em um Estado-nação, a Carta Magna ${ }^{2}$. Além disto, a carta assegurou a estados e municípios maior autonomia e descentralização político-administrativo em relação à União (VITALE, 2004). Situa-se, no espectro de mudanças, as iniciativas no campo da gestão orçamentária dos recursos públicos e o processo de constituição, disseminação e operação de instituições e mecanismos participativos.

Nesta linha, Leonardo Avritzer (2009) compreende enquanto possibilidade de cidadãos participarem e interferirem no processo de tomada de decisão política, via participação nas instituições participativas, à luz de três perspectivas: a primeira considera o desenho participativo de característica bottom-up dessas instituições, exemplo disso são as experiências do Orçamento Participativo $(\mathrm{OP})^{3}$ e da Consulta Popular $(\mathrm{CP})^{4}$; o segundo aspecto considera o desenho de partilha do poder, como ocorre nos conselhos deliberativos; a terceira e última perspectiva analisa o aspecto relativo ao desenho de ratificação pública, característica de cidadãos que participam de espaços públicos de discussão como audiências públicas ou na elaboração de planos diretores municipais.

A presença de instituições participativas nos três níveis de governo, isto é, no municipal, estadual e no federal, apresenta especificidades e particularidades,

1 O termo estado constitui a nomenclatura brasileira para nomear os entes que integram a federação: as regiões. Isto é, o Brasil constitui uma federação de 26 regiões acrescidas do Distrito Federal. Portanto, esta pesquisa, ao analisar o estado RS, está analisando uma região.

2 A Carta Magna é um termo que deriva do latim Magna Charta Libertatum, que faz menção à Constituição Federal do Brasil (CF). Em linhas gerais, a CF estipula um conjunto de instrumentos legais com vistas a garantir a legitimidade do sistema democrático, mas, sobretudo, assegura aos cidadãos um espectro de direitos e deveres, legitima o poder civil, definindo a democracia como representativa e participativa, e transferiu o poder do governo central para estados e municípios (MARQUETTI, 2003).

3 O OP consiste numa experiência de participação direta de cidadãos na esfera pública. Neste espaço, os cidadãos podem influenciar a administração pública sobre as decisões do orçamento, direcionando-o para setores da sociedade nos quais os participantes do processo julgam ser prioritários.

4 O Governo do RS realiza anualmente uma consulta direta à população para saber quais as áreas prioritárias devem receber investimento de ordem pública. O processo da $\mathrm{CP}$ vinha sendo realizado da combinação de votação através de cédulas e através do uso das TICS, em particular, por meio da internet. Em 2016, o processo passou a ser realizado somente por meio dos instrumentos tecnológicos, combinando um formato híbrido de votação, ou seja, a escolha das prioridades regionais pela população passou a se dar tanto através do uso da internet (online) como também por meio da escolha via dispositivos eletrônicos (off-line). Ver Lei no 11.179, de 25 de junho de 1998. 
principalmente ao introduzir no campo de pesquisa da ciência política e social, a discussão de alternativas frente ao atual modelo de desenvolvimento hegemônico das sociedades. Introduzir a temática do desenvolvimento regional, não somente é necessária para assegurar as particularidades da região como, também, se constituí num embate ao modelo democrático cunhado sob as bases do "mercado e sobre a desigualdade socioeconômica é uma farsa bem sucedida, visto que os mecanismos por ela acionados destinam-se apenas a conservar a impossibilidade de democracia" (SÁNCHEZ, 2002, p. 31). Ressalta-se a importância das decisões deliberadas pela população, por meio das instituições participativas, refletirem tal perspectiva.

É preciso acentuar que a participação dos cidadãos na $\mathrm{CP}$, via conselhos municipais e regionais, permite não só a descentralização do poder, como a sua (re)distribuição, privilegiando que as decisões tomadas reflitam os interesses coletivos frente aos interesses individuais. Parte-se da visão de Pires e López (2010, p. 565) para quem a organização política da participação e das tomadas de decisões possam contribuir para o desenvolvimento de "novas formas de mediação representativa entre Estado e sociedade".

Dada a relevância de vincular a perspectiva do desenvolvimento regional, o artigo consiste, a partir de uma linha participacionista/deliberacionista, em identificar comparativamente se os projetos prioritários eleitos por meio da participação da população na etapa municipal do processo de votação da Consulta Popular (CP) 2016-2017 dialoga com a perspectiva do desenvolvimento regional. A descrição comparativa se deu no âmbito local do Conselho Municipal de Desenvolvimento de Ijuí (Codemi) ${ }^{5}$ e, para o processo regional da CP, sob o recorte territorial do Conselho Regional de Desenvolvimento Noroeste Colonial $\left(\right.$ Corede-Norc ${ }^{6}$ ), enquanto instrumentos de governança territorial.

Em termos metodológicos, o estudo consiste numa abordagem qualitativa, de cunho bibliográfico e documental, no qual se analisou o Regimento Interno do Codemi, a ata com os resultados das demandas eleitas prioritárias por temática, o caderno de diretrizes da CP, comparando-os com o resultado da votação do Corede-Norc para a CP 2016-2017.

\footnotetext{
O Codemi/Comudes são um conselho consultivo-deliberativo de tomada de decisão. Os Comudes surgem em 2003/04 como funcionais ao processo de consulta popular, coordenado pelos Coredes e Governo do Estado.

6 O RS é formado por 28 microrregiões denominadas de Corede, e cada Corede é formado por um conjunto de municípios. Os Coredes são regulamentados Decreto 35.764 que regulamenta a Lei $\mathrm{n}^{\circ} 10.283$, de 17 de outubro de 1994, que criou os Coredes. Disponível em: <http://www.al.rs.gov.br/Legis/M010/M0100099.ASP?Hid_Tipo=TEXTO\&Hid_ TodasNormas=12439\&hTexto=\&Hid_IDNorma=12439> . Acesso em: 14 abr. 2017.
} 


\section{A VONTADE GERAL COMO PRESSUPOSTO NORTEADOR DA DEMOCRACIA PARTICIPATIVA E DELIBERATIVA}

As terminologias 'Democracia', 'Participação' e 'Deliberação' exprimem concepções teórico-conceituais indissociáveis de um ideário de sociedade contemporânea pautado na participação direta da sociedade civil na esfera governamental do Estado. Ao longo da história, foram utilizados como condição sine qua non na tentativa de se estabelecer uma relação entre sociedade e Estado que possibilitasse maior empoderamento da população.

A democracia enquanto um modelo de governo, a participação enquanto uma estratégia de consolidação democrática e a deliberação enquanto mecanismo de descentralização da tomada de decisão e empoderamento, expõem, em certa medida, uma visão teórica normativa que tenciona a democracia participativa/ deliberativa à luz de um ideal utópico, de como deve, ou deveria ser, o ideal democrático (ROUSSEAU, 1983; HARBERMAS, 1987).

É preciso acentuar que a noção de coletivo abordada neste estudo exprime a ideia de que as decisões tomadas no campo democrático - sejam elas de forma indireta pelos representantes eleitos pelo povo através do sufrágio universal, ou de forma direta pela população por meio da participação no campo político -, devam representar o interesse da maioria, isto é, a soma dos interesses coletivos da 'vontade geral' (CÓRDOBA, 2010).

A priori, a vontade geral prima por um sistema democrático no qual os cidadãos são os maiores beneficiados das políticas públicas, cabendo ao Estado resguardar os interesses coletivos frente aos interesses individuais, do setor privado, econômico, representado através da vontade de todos.

É necessário sublinhar a visão de Allebrandt (2002) ao expor o pensamento de que a ideia de democracia envolve, eminentemente, relações entre sujeitos e tomadores de decisões em relação aos modos de vida. Essas relações definem "políticas públicas que afetam tanto as instâncias governamentais quanto a sociedade civil em vários aspectos da vida em sociedade, considerando a complexidade de cada época e as ideias desenvolvidas" (p. 48).

Para Rawls (2001), uma sociedade democrática nem sempre é justa e isenta de interesses individuais. Não está a se dizer que não se possa ter interesses individuais, a crítica a se tecer é quando os interesses individuais sobressaem aos interesses coletivos. Uma democracia pensada à luz da coletividade requer a participação ativa de seus cidadãos, requer a presença de instrumentos de governança territorial que imprimem sentidos e significados ao mundo da vida no sentido de orientar as ações e a definição de políticas públicas em prol do bem comum. 
A Democracia Participativa/Deliberativa, pensada à luz da teoria da Ação Comunicativa ou comunicação linguística habermasiana, possibilita ao cidadão, ao menos no campo teórico, romper com dogmas que o inibem de manifestar o livre pensamento e o discurso aberto no mundo da vida. Trata-se de um processo cooperativo de interpretação, em que os participantes, por meio do processo dialógico, pautado no uso da razão, interagem entre si alinhando os argumentos até se chegar a um consenso comum. Ressalta-se, que ao intercambiar argumentos, ideias e informação, os participantes devem fazê-lo de modo a evitar a supressão da fala do outro, tornando assim o processo participativo mais democrático possível.

Habermas (1987) compartilha da ideia de que além do direito a fala, num processo participativo, deve-se ainda fazer uso da razão ao se tomar decisões. A racionalidade comunicativa que este autor menciona não visa substituir a racionalidade instrumental - uso da técnica - do processo participativo, pois esta última diz respeito a operacionalização daquilo que é discutido no campo dos processos dialógicos.

A exemplo do ideário normativo habermasiano de espaço público, enfatiza-se que o mesmo deve privilegiar a emancipação cidadã, contemplar procedimentos racionais, discursivos, participativos e pluralistas, e mesmo orientados por interesses técnico-instrumentais, devem propiciar condições de a sociedade civil estabelecer um consenso comunicativo e uma autorregulamentação (HABERMAS, 1987). Neste caso, a racionalidade instrumental deve estar subordinada a racionalidade comunicativa, e não o contrário. Todavia, por vezes, nos espaços participativos, as tomadas de decisão são pautadas no uso da racionalidade instrumental, suprimindo a racionalidade comunicativa.

$\mathrm{Na}$ atual dinâmica de ordenamento do território, a racionalidade comunicativa acaba por vezes sendo suprimida pela racionalidade instrumental. Haja vista que o território não é um espaço neutro, mas um ambiente marcado por conflitos, disputas, um espaço construído para atender, quase que sumariamente, os interesses dos grandes grupos hegemônicos que desconsideram as especificidades e particularidades da região (ETGES, 2001).

A descentralização decisória na esfera pública, principalmente por meio dos conselhos municipais de desenvolvimento, tem se consolidado cada vez mais em democracias participativas. Faz-se importante ressaltar que nem sempre a tomada de decisão ocorre de forma a propiciar o entendimento mútuo ou o bem comum, ou mesmo são atendidos os interesses coletivos. 


\section{COREDESECOMUDESCOMO EXPERIÊNCIADE PARTICIPAÇÃO NO RS}

A experiência do RS com os Coredes e Comudes, possibilitou significativos avanços no bojo da manutenção da democracia participativa e deliberativa no estado. A participação no RS, em que pese o campo normativo constitucional, é compreendido como um princípio da administração pública. De acordo com o Art. 19 da Constituição Estadual (CE) de 1989 do estado do RS, a participação na administração pública se dá

[...] direta e indireta de qualquer dos Poderes do Estado e dos municípios, visando à promoção do bem público e à prestação de serviços à comunidade e aos indivíduos que a compõe, observará os princípios da legalidade, da moralidade, da impessoalidade, da publicidade, da legitimidade, da participação, da razoabilidade, da economicidade, da motivação.

A CE foi inspirada na então recente promulgação da Constituição Federativa do Brasil (CF) de 1988, que já destacava um conjunto de elementos de democracia direta e semidireta para o exercício democrático em todas as dimensões do Estado.

Após a experiência brasileira com o regime militar, que perdurou duas décadas (1964-1985), a redemocratização do Brasil com a elaboração da CF alterou o modus operandi de se governar. Instituiu-se formas de regulação participativa e solidária, de reconstrução do espaço público e legitimação do mandato político, de emancipação dos indivíduos.

Neste contexto, não se pode esquecer de enfatizar que no atual modelo democrático brasileiro, de gestão descentralizada, com participação cidadã, a perspectiva municipal (local) é a primeira instância de contato dos cidadãos com os órgãos públicos. É, ainda, a instância onde ocorre a concretização das políticas públicas nos diferentes níveis político-administrativo do Estado.

A experiência de descentralização político-administrativa do RS resultou na institucionalização de diversos instrumentos de governança territorial (GT). Na perspectiva de Ferrão (2010), a partir do caso português, a GT valoriza a descentralização dos processos de decisão

face ao papel tradicionalmente desempenhado pelo Estado moderno, nuns casos desenvolvidos no âmbito de contextos mais desregulamentados, noutros [...] em mecanismos mais participativos, organizados em rede e colaborativos (FERRÃO, 2010, p. 133). 
Na concepção de Dallabrida (2012, p. 6) a governança territorial exprime a ideia de um "conjunto de iniciativas ou ações que expressam a capacidade de uma sociedade organizada territorialmente para gerir os assuntos públicos a partir do envolvimento conjunto e cooperativo dos atores sociais, econômicos e institucionais".

Por assim dizer, a governança territorial pode ser analisada tanto pelo prisma normativo de aplicação dos princípios da boa governança, até pelo viés das políticas territoriais e urbanas, como um processo de planejamento e gestão de dinâmicas territoriais. Sendo, neste segundo olhar, inovador, partilhado e colaborativo.

Num modelo de governança, pressupõem-se que haja maior cooperação entre sujeitos, governo, mercado, cujas políticas, tanto de base territorial como setorial, são mais articuladas com os interesses do coletivo.

Cabe mencionar, que os Coredes enquanto fóruns de discussão, decisão e integração de políticas, ações, lideranças e recursos orientados à promoção do desenvolvimento regional no Rio Grande do Sul, são exemplos de instrumentos de governança territorial. Os mesmos foram instituídos através da Lei n 10.283 , de 17 de outubro de 1994, e regulamentados através do Decreto n 35.764, de 28 de dezembro de 1994. De acordo com o que preconiza a Lei, eles têm por objetivo: a promoção do desenvolvimento regional harmônico e sustentável; a integração dos recursos e das ações do Governo e da região; a melhoria da qualidade de vida da população; a distribuição equitativa da riqueza produzida; o estimulo à permanência do homem em sua região; a preservação e recuperação do meio ambiente. Atualmente são 28 Coredes no estado do Rio Grande do Sul.

Os Comudes são outro exemplo de instrumentos de governança territorial. Assim como os Coredes, os Comudes representam o espaço físico onde a mobilização e deliberação do interesse coletivo se concretiza. No entanto, algumas peculiaridades os diferenciam um do outro. Enquanto os Coredes se organizam de forma descentralizada e representam um arranjo de municípios gaúchos, os Comudes também se organizam de forma descentralizada, mas sua atuação se dá na instância municipal. Todavia, é possível que as deliberações deste conselho visem o regional e não tão somente o local.

Pode-se dizer, que Coredes e Comudes são arranjos institucionais que possibilitam atingir níveis democráticos de participação mais consolidados. Numa democracia participativa a capacidade de mobilização e articulação política e social entre as múltiplas escalas do território é fundamental para a manutenção do processo participativo. 
Cabe lembrar, que estes arranjos institucionais formam a base do processo de regionalização do executivo do RS, que busca reconhecer diversas formas de mobilização, participação e articulação da sociedade, fomentando, assim, uma cultura participativa no estado. Os avanços na democracia participativa possibilitam que o cidadão seja soberano de suas ações e decisões atuando em prol do exercício da cidadania (BONAVIDES, 2008).

\section{CARACTERIZAÇÃO DO LÓCUS DO ESTUDO}

O município de Ijuí foi oficialmente fundado em 19 de outubro de 1890. De acordo com Allebrandt (2002), nesta época, Ijuí era uma colônia sob tutela de um governo central. Sob o ponto de vista étnico, prevalecia o modelo de centros hegemônicos, isto é, o povoamento das colônias se dava por integrantes de um mesmo grupo étnico, geralmente por italianos e alemães. Entretanto, sua emancipação para município só ocorreu na primeira metade do século XX, em 1912.

Com a emancipação política do município as colônias passaram a ser ocupadas por imigrantes vindos de outras regiões da Europa. Além dos grupos étnicos que predominavam nesta região (italianos e alemães), outros grupos como poloneses, portugueses, espanhóis, franceses, letos, suecos, húngaros, também começaram a ocupar esta região do estado do RS (ALLEBRANDT, 2002).

Com relação aos dados sociodemográficos, Ijuí possui uma população de 78.915 habitantes. Destes, 71.550 (90,67\%) habitantes residem na área urbana, o qual revela a existência de um alto grau de urbanização, pois apenas 7.365 (9,33\%) residem na área rural (IBGE, 2010). Ao comparar estes dados com o Censo Demográfico de 2000, percebe-se um acentuado êxodo rural. Em 2000, o total de habitantes era de 78.286. Destes, 67.181 (85,8\%) residiam no meio urbano e 11.105 (14,2\%) no meio rural. Em dez anos aumentou em 5\% o percentual da população que migrou da zona rural para a urbana.

Em relação aos indicadores socioeconômicos, o $\mathrm{PIB}^{7}$ municipal de Ijuí, no ano de 2012, foi de $\mathrm{R} \$ 2.760 .178,00$. Destes, $2.187 .717,08$ (79,26\%) são provenientes de prestação de serviços, $379.800,49$ (13,76\%) são da indústria e 192.660,42 (6,98\%) são da agropecuária. Isto desmistifica que a cultura de Ijuí essencialmente agrícola, pois se destaca nos segmentos pecuário, comércio, indústria e serviços. Porém, se salienta que a indústria e a prestação de serviços podem estar diretamente relacionadas ao primeiro setor.

Disponível em: <http://www.fee.rs.gov.br/wp-content/uploads/2015/12/20151217pibmunicipal-total-per-capita-2013.xlsx>. Acesso em: 29 abr. 2017. 
Já em relação ao Índice de Desenvolvimento Humano Municipal (IDHM), segundo a classificação do $\mathrm{PNUD}^{8}$, Ijuí ocupa a décima terceira $\left(13^{\circ}\right)$ posição no ranking dos 497 municípios gaúchos com melhor IDHM com 0,781. No mapa da Figura 1, é possível localizar o município de Ijuí a partir da subdivisão regional do Corede Noroeste Colonial Gaúcho.

Figura 1 - Localização do município de Ijuí a partir do recorte territorial do Corede-Norc

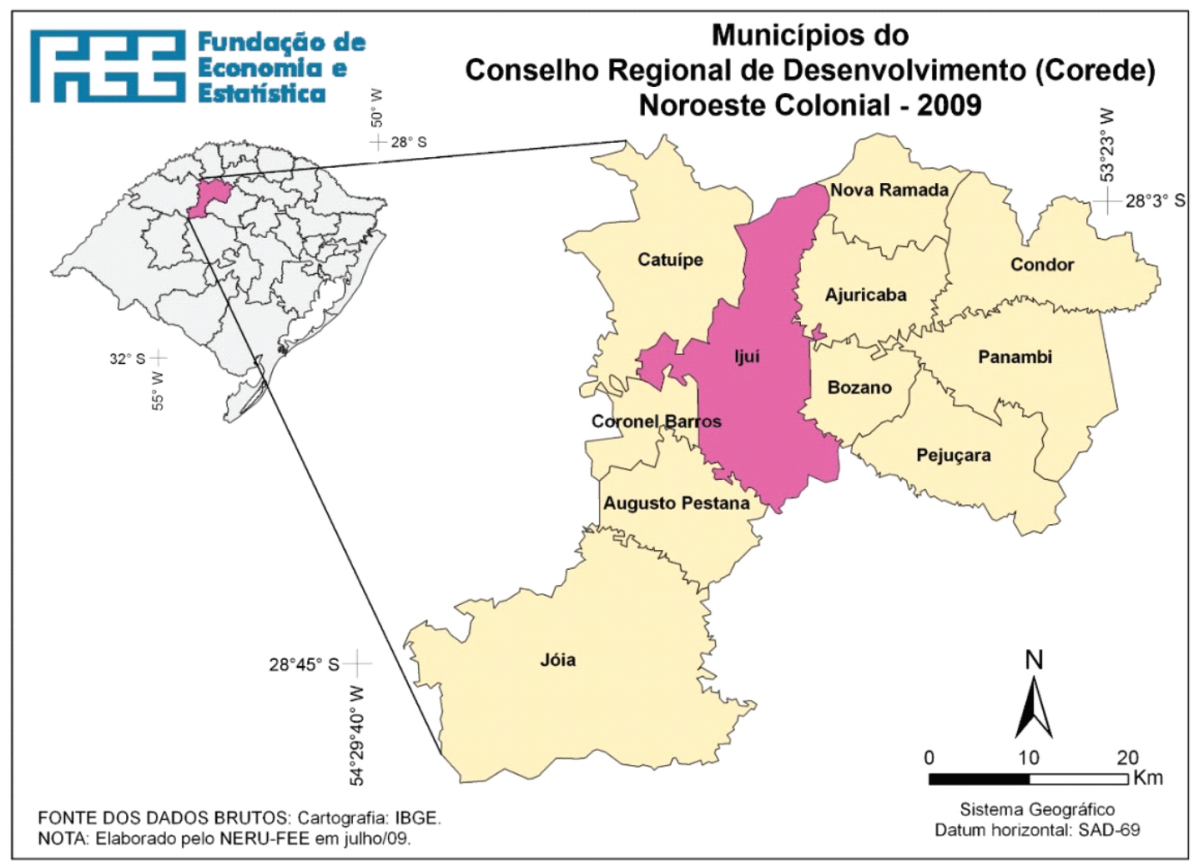

Fonte: Portal do Corede-Norc ${ }^{9}$ - Adaptado pelo autor.

Outro ponto importante a destacar sobre Ijuí, e que vai ao encontro do tema proposto neste artigo, é a sua experiência em relação ao desenvolvimento de práticas participativas deliberativas através dos conselhos municipais, meios estes que se caracterizam como espaços públicos de relacionamento e cooperação entre a sociedade civil e a esfera governamental.

No Plano Diretor ${ }^{10}$ de Ijuí, o artigo 10, inciso X, por exemplo, expõe a preocupação em se garantir a legitimidade de espaços de participação plurais, sendo objetivo da Política Municipal Participativa de Desenvolvimento de Ijuí

\footnotetext{
Disponível em: <http://www.atlasbrasil.org.br/2013/pt/ranking>. Acesso em: 29 abr. 2017.

Disponível em: < http://www.coredenorc.org.br/index.php/comudes>. Acesso em: 29 abr. 2017.

10 O Plano Diretor é um instrumento de política de desenvolvimento urbano e da expansão urbana do município, orientando as ações dos agentes públicos e privados na produção e gestão da cidade e das outras áreas urbanas de Ijuí.
} 
“instituir o Sistema Municipal de Planejamento e Gestão Participativa, garantindo canais de participação democrática nos processos de tomada de decisão" e no inciso XI "integrar o planejamento local ao desenvolvimento regional, através da articulação com os demais municípios da região".

Já o artigo 24, inciso III, também visa "garantir a participação popular, individual ou coletiva, através da criação de canais de participação da sociedade na gestão municipal da Política de Desenvolvimento [...]”. Desta forma, é importante frisar que o Plano Diretor atua no sentido de ser mais um instrumento que, se bem elaborado, reforça ainda mais a conquista e o empoderamento da sociedade civil na discussão dos problemas, na definição das prioridades, na implementação das ações e na avaliação e fiscalização das políticas públicas (controle social accountability) a nível local.

Allebrandt (2002) reforça a ideia de que a participação da comunidade ijuiense no Planejamento Estratégico Participativo de Ijuí, nos processos de planejamento setoriais (saúde, educação, turismo, etc.), no Plano Plurianual, na Lei de Diretrizes Orçamentárias (LDO) e na elaboração do Orçamento Anual, é resultado de um amplo esforço realizado há várias décadas entre os órgãos públicos, a sociedade civil e também em parecia com a universidade local.

Um exemplo desse esforço foi a construção do PPA realizado em Ijuí no ano de 2009 que serviu de exemplo para a construção do PPA do estado do Rio Grande do Sul, elaborado de forma participativa sob a coordenação da Secretaria de Planejamento do Estado e os Coredes, em 2011. Ijuí, adota como nomenclatura Plano Plurianual Comunitário Participativo, pois a construção do mesmo se dá com o apoio da comunidade. Outro instrumento que incorpora a palavra comunitário é o Orçamento Participativo, passando a ser chamado de Orçamento Comunitário Participativo de Ijuí. Estes instrumentos constituemse em processos de participação direta da comunidade, com o objetivo de debater, propor, deliberar e fiscalizar as políticas públicas indutoras para o desenvolvimento integrado de médio/longo prazo do município ou do estado.

\section{O CONSELHO DE DESENVOLVIMENTO DO MUNICÍPIO DE IJUÍ - CODEMI/COMUDE}

Com a Constituição Federal de 1988, marco que representa a redemocratização do país e a conquista de inúmeros direitos políticos, civis e sociais, assim como mecanismos instituídos para assegurar a participação cidadã nos assuntos relacionados ao Estado e à defesa de seus direitos (SILVEIRA; ALLEBRANDT; CAMPOS, 2015). 
O processo, em curso, de redemocratização do país, segue uma lógica de descentralização político-administrativa do Estado. Em outras palavras, isso quer dizer que há uma distribuição do poder do governo federal (central) a estados e municípios, valorizando os níveis subnacionais de governo.

Assim, a maior autonomia a estados e municípios - mas especialmente a municípios -, pode, segundo Allebrandt (2002, p. 73), "possibilitar novas formas de gestão pública modernas e democráticas como pode representar a persistência de práticas políticas patrimonialistas, que impedem a consolidação da cidadania e da democracia”.

Os Coredes, assim como os Comudes, são exemplos de como a gestão pública, por meio da participação cidadã, pode evitar práticas patrimonialistas, clientelistas, a ineficiência, a ingovernabilidade e a irresponsabilidade fiscal na condução da gestão pública.

A instituição dos conselhos municipais, em todos os municípios do território nacional, se deu após a promulgação da CF de 1988, mais especificadamente na década de 1990. Os conselhos municipais atuam de forma estratégica na condução do bem público, corroboram para que se mantenha o princípio da eficiência na administração pública e ainda atuam de forma articulada com o governo local, a esfera do mercado e da sociedade civil. Para este autor, os conselhos municipais são espaços públicos que legitimam a participação da sociedade civil na gestão pública local. Frutos do processo de descentralização (municipalização) das políticas sociais, os

Conselhos apresentam-se idealmente como elemento de ligação na relação da sociedade civil com o Estado. Têm a responsabilidade de orientar/definir as políticas, acompanhar sua implementação e fiscalizar a qualidade dos serviços, seja do ensino, da saúde, dos programas de emprego e renda, da assistência social etc. São, portanto, os conselhos municipais que deveriam consubstanciar a efetividade dos processos de participação na gestão pública, na busca de uma democracia cidadã real (ALLEBRANDT, 2002, p. 73- 74).

O Codemi foi fundado em 10 de março de 1992 por meio da Lei Municipal $\mathrm{n}^{\mathrm{o}}$ 2.743, mas somente dois anos mais tarde com o Decreto Executivo n ${ }^{\circ} 1.798$, de 04 de abril de 1994, foi aprovado o primeiro regimento interno deste conselho. É classificado como pessoa jurídica de direito privado, organizado sob a forma de associação civil, sem fins lucrativos, sua área de abrangência não ultrapassa os limites geográficos do município de Ijuí. Cada Comude atua de forma a respeitar os limites da jurisdição de seu município de origem, ou seja, somente atuam dentro do respectivo município ao qual foram criados. Além do mais, contam 
com a representação e participação da sociedade civil e das diferentes instâncias dos poderes públicos locais.

A Lei Municipal no 5.438 de 2014, em seu artigo 1, apresenta-o como “órgão deliberativo de assessoramento e cooperação [...], vinculado à Secretaria Municipal de Planejamento e Regulação Urbana”. No artigo 3, estão descritos os princípios que norteiam a sua ação:

I. Promoção do desenvolvimento local;

II. Autonomia, isenção e neutralidade em relação às diferentes instâncias governamentais, à correntes político-partidárias e à organizações;

III. Reconhecimento da individualidade do ser humano e de sua condição indeclinável de sujeito da história;

IV. Respeito à pluralidade de concepções, buscando sempre construir consensos em torno de temas de interesse para o desenvolvimento do município;

V. Democracia representativa e participativa;

VI. Visão do município como unidade integral e integrada, considerado como parte da região do estado e do país onde se localiza;

VII. Cooperação, parceria e respeito à autonomia de todas as instituições representadas no Conselho;

VII. Esforço permanente no sentido de aumentar a sua representatividade e a sua organização;

IX. Apoio à continuidade das políticas públicas de interesse para o desenvolvimento do município.

A partir dos princípios estabelecidos no Regimento Interno, sob tutela da Lei Municipal $n^{\circ}$ 5.438, o Codemi, no artigo 4, apresenta seis objetivos-chave:

I. Promover o desenvolvimento local harmônico e sustentável, visando à melhoria da qualidade de vida, à distribuição equitativa da riqueza produzida, à permanência das pessoas em seu município e à preservação e recuperação ambiental;

II. Viabilizar a participação plural dos cidadãos e das organizações da sociedade local na elaboração e gestão do plano municipal de desenvolvimento, constituindo-se em espaço de construção da cidadania interativa;

III. Promover a articulação entre as entidades e os demais Conselhos Municipais Setoriais e Temáticos e propor ações ao Poder Público Municipal, Estadual e Federal, visando o desenvolvimento econômico e social harmônico e integrado;

IV. Elaborar e priorizar projetos a serem propostos pela comunidade local junto ao Conselho Regional de Desenvolvimento e as demais instâncias de discussão e deliberação popular e participativa;

V. Fortalecer a cultura e a vivência da participação democrática na gestão da comunidade local;

VI. Promover a disseminação de informações relevantes para o desenvolvimento local e regional, qualificando a participação. 
Em relação a estrutura e composição do Codemi, o mesmo é formado por um Fórum Municipal de Desenvolvimento de Ijuí; Assembleia do Codemi; Conselho de Representantes do Codemi; Comissões Permanentes; Comissões Temáticas Especiais; e pelo Núcleo de Coordenação do Codemi.

Neste artigo explanar-se-á apenas brevemente as duas primeiras instâncias da estrutura e composição do Codemi, o Fórum Municipal de Desenvolvimento e a Assembleia do Codemi, pois entende-se que essas duas composições são as mais importantes deste conselho.

O Fórum Municipal de Desenvolvimento, “constitui-se no espaço público mais amplo para a discussão comunitária da problemática e potencialidades do desenvolvimento local e regional, com vistas à definição das diretrizes estratégicas para orientar o Plano Estratégico Participativo de Ijuí”. Cabe destacar ainda que ele é composto por "todas as entidades que integram a Assembleia do Codemi, outras entidades não credenciadas para a Assembleia e os cidadãos interessados na discussão do desenvolvimento" (REGIMENTO INTERNO, Capítulo III, Seção I, Art. $7^{\circ}$ e $8^{\circ}$ ).

A Assembleia Geral Municipal, de acordo com o Art. no 9 do Regimento Interno, é o órgão máximo de deliberação do Codemi. Ela é constituída por todos os cidadãos que comprovem através de título eleitoral e/ou cédula de identidade domicílio no município. Compete a ela: eleger os membros não natos do Conselho de Representantes do Codemi, apreciar e deliberar sobre o Plano Estratégico Participativo de Desenvolvimento de Ijuí, apreciar e aprovar o Regimento Interno do Codemi e discutir e deliberar sobre assuntos demandados pelo Codemi (REGIMENTO INTERNO, Capítulo III, Seção II, Art. 9º).

\section{DESCRIÇÃO DAS PROPOSTAS ELEITAS PELO CODEMI E COREDE-NORC NA CP 2016-2017}

Realizou-se em 02 de junho de 2016, no município de Ijuí, a Assembleia Pública Municipal para votação das prioridades municipais relativas à CP 2016/2017, a partir dos objetivos estabelecidos no Regimento Interno do Codemi, que tratam sobretudo de promover a articulação entre as entidades e os demais Conselhos Municipais Setoriais e Temáticos e propor ações ao Poder Público Municipal, Estadual e Federal, visando o desenvolvimento econômico e social harmônico e integrado, bem como de elaborar e priorizar projetos a serem propostos pela comunidade local junto ao Corede e as demais instâncias de discussão e deliberação popular e participativa. 
De acordo com a distribuição dos recursos da CP 2016 para o orçamento 2017, o governo do RS deliberou o montante de $\mathrm{R} \$ 50.000 .000,00$ a serem distribuídos entre os 28 Coredes. Inicialmente, foi pré-fixado igualitariamente o valor de $\mathrm{R} \$ 1.000 .000,00$ para cada um dos 28 conselhos regionais. De modo que este valor contemplasse as 8 áreas temáticas definidas no caderno de diretrizes da CP 2016-2017, que foi elaborado pela Secretária do Planejamento, Mobilidade e Desenvolvimento Regional do Estado do RS (Seplan/RS). Após esse rateio, foi acrescido ao montante pré-fixado um percentual por região considerando o Índice de Desenvolvimento Humano (IDESE) e a população total de cada região.

Desta forma, cada região deliberou sobre um valor distinto. Destaca-se que o menor valor deliberado foi para o Corede Rio da Várzea (R\$1.207.049,99). Enquanto que o maior valor foi para o Corede Metropolitano do Delta do Jacuí ( $\mathrm{R} \$ 4.838 .551,56)$. Já para o Corede-Norc, região na qual o Codemi está inserido, foram destinados $\mathrm{R} \$ 1.264 .227,12$. Como integram a região do Corede-Norc 11 municípios, este valor total será aplicado de modo a contemplar todos os municípios integrantes da região.

É oportuno citar as áreas temáticas definidas para o processo da CP 20162017. As 8 áreas são: 1) Agricultura, Pecuária e Irrigação; 2) Desenvolvimento Rural; 3) Turismo, Esporte e Lazer; 4) Cultura; 5) Desenvolvimento Econômico, Ciência e Tecnologia; 6) Minas e Energia; 7) Educação; e 8) Saúde.

A partir das oito áreas temáticas, no caso do Codemi, a população definiu 4 projetos prioritários que foram encaminhados a etapa regional da CP. Os projetos apresentados pela comunidade em Assembleia Pública Municipal, foram apresentados pelos solicitantes justificando os motivos pelos quais deveriam ser definidos como prioritários, para, assim, compor a cédula final de votação regional. Caso nesta etapa o projeto fosse um dos mais votados, estaria apto a receber o recurso público. Os projetos demandados pela população na fase de defesa na Assembleia Pública Municipal que tivessem proximidades um com o outro, foram agrupados de modo a torná-los uma só demanda. Ressalta-se que as propostas deveriam estar em consonância com os itens do caderno de diretrizes, do contrário, haveria a supressão das mesmas.

De acordo com a Ata de Assembleia Pública Municipal, as propostas eleitas como prioridade municipal para compor a cédula de votação da Consulta Popular 2016/2017 foram:

I. Agricultura, Pecuária e Irrigação (SEAPI) - Apoio à cadeia produtiva do leite. Distribuição de insumos.

II. Desenvolvimento Rural (SDR) - Apoio a Agroindústria Familiar. Aquisição de equipamentos. 
III. Desenvolvimento Econômico, Ciência e Tecnologia (SDECT) Redes de Cooperação. Apoio a micro, pequenas e médias empresas em toda a região noroeste colonial;

IV. Saúde (SES) - Qualificação e financiamento da rede de atenção. Aquisição de equipamentos para hospitais de referência regional - acima de 70 leitos.

Um ponto a se destacar quanto as áreas temáticas, diz respeito ao fato da área da segurança pública, historicamente contemplada na CP, não estar presente enquanto temática na CP. Percebe-se que as prioridades eleitas pelos cidadãos ijuienses no âmbito do Codemi não dialogam com a perspectiva do desenvolvimento regional, subentendido como sendo a união de esforços conjuntos, mormente articulados entre regiões com identidades em comum, que tem por finalidade

potencializar sua capacidade de auto-organização, transformando uma sociedade inanimada, segmentada por interesses setoriais, pouco perceptiva de sua identidade territorial e definitivamente passiva, em outra, organizada, coesa, consciente de sua identidade, capaz de mobilizar-se em torno de projetos políticos comuns, ou seja, capaz de transformar-se em sujeito de seu próprio desenvolvimento (ETGES, 2001, p. 10).

Isto é, ações de desenvolvimento regional visam as particularidades, as diversificações de cada região. Neste sentido, as demandas eleitas como prioridade pelo Codemi, não proporcionam a integração dos municípios sob o ponto de vista da unificação da região em prol da potencialização de suas identidades regionais, a fim de fortalecê-los frente a homogeneização do capital. Todavia, os itens III e IV, que tratam de fornecer incentivos/apoio a micro, pequenas e médias empresas em toda a região noroeste colonial, bem como a aquisição de equipamentos para hospitais de referência regional - acima de 70 leitos são tratados no processo da consulta e, consequentemente, são votados pelos munícipes de Ijuí, como sendo áreas de abrangência regional. Como aborda Santos (1997), o fortalecimento das regiões perpassa a adoção de um conjunto de estratégias de valoração das particularidades, das especificidades, do endógeno a partir de uma perspectiva horizontal bottom-up, que engloba as questões sociais, culturais, ambientais, históricas.

Para Santos (1997), a particularidade se dá no lugar/local, é no local que o homem descobre que não está isolado e o lugar torna-se o mundo do veraz e da esperança. Embora na literatura acadêmica haja um espectro de teorias que abordam as diferenças entre desenvolvimento local e regional e sua importância, compreende-se que a terminologia do regional dos itens III e IV, são utilizadas 
meramente para afirmar que uma ação não se restringe a apenas um município, mas a um conjunto deles. Diferentemente da visão de Etges sobre o significado de pensar o regional. Portanto, não foi possível identificar nenhuma prioridade com esse viés.

$\mathrm{Na}$ instância regional, todas as 4 prioridades eleitas pelo Codemi, foram contempladas na Consulta Popular 201611. Respectivamente, o item I - o apoio à cadeia produtiva do leite (distribuição de insumos) - recebeu um valor total de $\mathrm{R} \$ 41.245,00$. O item II - apoio a agroindústria familiar (aquisição de equipamentos) - recebeu o montante de $\mathrm{R} \$ 36.660,00$. Já o item III - apoio à micro, pequenas e médias empresas em toda a região noroeste colonial (atuação com foco nos microempreendedores individuais) - recebeu o valor de R $\$$ 54.361,77. Com relação ao item IV - apoio a qualificação e financiamento da rede de atenção (aquisição de equipamentos para hospitais de referência regional - acima de 70 leitos), foi contemplado com $\mathrm{R} \$ 450.000,00$.

A partir da descrição do resultado final das votações da CP a nível regional ${ }^{12}$, pode-se dizer que as propostas eleitas não estão alinhas com a construção de uma agenda de propostas que contemple a perspectiva do desenvolvimento regional, embora sejam propostas tidas como importantes para a região.

No Quadro 1, constam as demandas aprovadas no Corede-Norc por município e o respectivo valor empenhado.

Quadro 1 - Demandas eleitas por município

\begin{tabular}{|c|c|c|c|c|}
\hline \multicolumn{5}{|c|}{ COREDE NOROESTE COLONIAL } \\
\hline Valor total & \multicolumn{4}{|c|}{$\mathrm{R} \$ 1.264 .227,12$} \\
\hline Classificação & 1 & 2 & 3 & 4 \\
\hline $\begin{array}{l}\text { Programas } \\
\text { eleitos }\end{array}$ & $\begin{array}{l}\text { SAÚDE - Qua- } \\
\text { lificação e fi- } \\
\text { nanciamento da } \\
\text { rede de atenção } \\
\text { - Consolidando } \\
\text { a regionalização } \\
\text { da saúde. }\end{array}$ & $\begin{array}{l}\text { DESENVOL- } \\
\text { VIMENTO } \\
\text { RURAL - Apoio } \\
\text { à agroindústria } \\
\text { familiar. }\end{array}$ & $\begin{array}{l}\text { AGRI- } \\
\text { CULTURA } \\
\text { - Apoio à ca- } \\
\text { deia produtiva } \\
\text { do leite e da } \\
\text { pecuária de } \\
\text { corte. }\end{array}$ & $\begin{array}{l}\text { CIÊNCIA E } \\
\text { TECNOLO- } \\
\text { GIA - Redes } \\
\text { de Coopera- } \\
\text { ção. }\end{array}$ \\
\hline$\%$ de divisão & $43,50 \%$ & $26,10 \%$ & $26,10 \%$ & $4,30 \%$ \\
\hline $\begin{array}{l}\text { Valor desti- } \\
\text { nado }\end{array}$ & $\mathrm{R} \$ 549.938,80$ & $\mathrm{R} \$ 329.963,28$ & $\mathrm{R} \$ 329.963,28$ & $\mathrm{R} \$ 54.361,77$ \\
\hline $\mathbf{N}^{\circ}$ de Votos & 5422 & 3184 & 2727 & 507 \\
\hline
\end{tabular}

11 Resultado final das demandas da Consulta Popular 2016 para Ijuí. Disponível em: < http:/ /www. consultapopular.rs.gov.br/wp-content/uploads/2015/07/NOROESTE-COLONIAL-2. pdf $>$. Acesso em: 02 maio 2017.

12 Resultado final das demandas da Consulta Popular 2016 no âmbito do Corede-Norc. Disponível em: <http://www.consultapopular.rs.gov.br/wp-content/uploads/2015/07/NOROESTECOLONIAL-2.pdf>. Acesso em: 28 abr. 2017. 


\begin{tabular}{|l|r|r|r|r|}
\hline MUNICÍPIOS & & & & \\
\hline Ajuricaba* & 68 & $* 484$ & 31 & 5 \\
\hline $\begin{array}{l}\text { Augusto Pes- } \\
\text { tana* }\end{array}$ & $* 193$ & $* 367$ & $* 476$ & 7 \\
\hline Bozano* & 61 & $* 131$ & $* 199$ & $* 8$ \\
\hline Catuípe* & 106 & $* 331$ & $* 442$ & 6 \\
\hline Condor* & 50 & $* 590$ & $* 574$ & 6 \\
\hline Coronel Barros* & 211 & 26 & $* 112$ & $* 45$ \\
\hline Ijui* & 2918 & $* 551$ & $* 289$ & $* 379$ \\
\hline Joia* & 47 & $* 248$ & 15 & $* 12$ \\
\hline Nova Ramada* & $* 1657$ & $* 75$ & $* 146$ & 1 \\
\hline Panambi* & 17 & $* 380$ & 38 & $* 38$ \\
\hline Pejuçara* & & 1 & $* 405$ & 0 \\
\hline
\end{tabular}

Fonte: Consulta Popular 2016, adaptado pelo autor.

Destaca-se, que o valor empenhado para a área temática da Saúde - qualificação e financiamento da rede de atenção - representa 43,50\% ( $\mathrm{R} \$ 549.938,80)$ do total de $\mathrm{R} \$ 1.264 .227,12$ destinado ao processo da CP. Dos 11 municípios, apenas 6 foram classificados.

Em relação à área do desenvolvimento rural, cujo foco foi para o apoio à agroindústria familiar, em especifico à construção e reforma de agroindústrias, aquisição de equipamentos, totalizou R \$329.963,28 (26,10\%). Dos 11 municípios, 9 foram classificados. $\mathrm{Na}$ área temática da agricultura, com ênfase ao apoio à cadeia produtiva do leite e da pecuária de corte, o valor empenhado e o percentual em relação ao total destinado para o Corede-Norc foram o mesmo da área do desenvolvimento rural, isto é, $\mathrm{R} \$ 329.963,28$ (26,10\%). As prioridades foram para a compra de equipamentos e distribuição de insumos, sendo que dos 11 municípios, apenas 8 foram contemplados.

No que tange à área da ciência e tecnologia, com ênfase nas redes de cooperação, o total empenhado foi de $\mathrm{R} \$ 54.361,77$ (4,30\%). Este valor será destinado a 5 municípios.

Desta forma, pode-se dizer que os projetos deliberados no Codemi estão em conformidade com os objetivos estabelecidos no seu Regimento Interno, especialmente o primeiro que aborda a promoção do desenvolvimento local. Ou seja, entende-se que as demandas eleitas como prioridades, bem como aquelas que se efetivaram por meio da votação regional da CP, estão alinhados com o diagnóstico e com a análise situacional da região, em termos de problemas e alternativas a serem priorizadas.

Ressalta-se, no entanto, que existem desafios a serem superados para que, de fato, as demandas eleitas pelos munícipes correspondam a perspectiva do 
desenvolvimento regional. Entre elas, destacam-se o baixo valor destinado para os projetos, uma vez que o recurso é pulverizado entre todos os municípios que compõe a região. Outro fator a considerar é a demora para o repasse das verbas do governo para o processo, bem como quando as verbas não são repassadas. Fato este que pode gerar desestímulo à participação.

\section{CONSIDERAÇÕES FINAIS}

Constata-se que o Codemi possui uma importante relevância para o desenvolvimento do município de Ijuí. Integrado e articulado com os demais conselhos municipais, amplia o poder dos mesmos no processo de interação com o Poder Público Local. É por meio dele que a população pode participar da definição das prioridades e dos investimentos do recurso público junto ao governo estadual do RS.

Embora o Codemi se caracterize como um instrumento de governança territorial, com potencialidades democráticas participacionista deliberativas, ainda é preciso que os projetos eleitos como prioridade contemplem a perspectiva do desenvolvimento regional, de modo a se pensar as particularidades da região.

Constata-se, que o valor disponível deliberado no conselho municipal de Ijuí não possibilita que todas as demandas da sociedade sejam atendidas. Acredita-se que o baixo valor disponível aplicado à deliberação seja um dos maiores empecilhos deste conselho, o que acaba, por conseguinte, aumentando a descrença e a desmotivação dos participantes junto a este processo de participação. Essa desmotivação e descrença no processo ocorrem, possivelmente, por duas razões: os atrasos no repasse, ou o não pagamento; e também o fato de suas prioridades não serem eleitas.

Ressalta-se, ainda, que as demandas eleitas pelo Codemi não promovem o desenvolvimento regional, o que evidencia o desafio de se pensar em uma agenda nessa perspectiva. Espera-se que a participação da sociedade civil nestas instâncias de participação e deliberação, possa contribuir para a promoção do desenvolvimento regional. Assim, o Estado deve priorizar as instâncias deliberativas de participação, ser uma gestão pública descentralizada, aonde os sujeitos não sejam meros agentes receptores das decisões políticas, mas sujeitos protagonistas das mudanças sociais, que participam ativamente de todas as etapas do processo de participação, como na elaboração, no planejamento e na avaliação das políticas públicas. 


\section{REFERÊNCIAS}

ALLEBRANDT, Sérgio Luís. A participação da sociedade na gestão pública local e na produção das políticas: a atuação dos conselhos municipais de IjuíRS, de 1989 a 2000. Ijuí: Ed. Unijuí, 2002. 264p. (Coleção Trabalhos AcadêmicoCientíficos. Série Dissertações de Mestrado, 32)

AVRITZER, Leonardo. Participatory institutions in democratic Brazil. Baltimore: John Hopkins University Press, 2009.

BRASIL. Constituição da República Federativa do Brasil. Brasília, 1988. Disponível em: <http://www.planalto.gov.br/ccivil_03/constituicao/constituicao. htm>. Acesso em: 29 abr. 2017.

Constituição do Estado do Rio Grande do Sul. Porto Alegre, 1989.

BONAVIDES, Paulo. Teoria da Democracia Participativa: Por um Direito Constitucional de luta e resistência. Por uma Nova Hermenêutica. Por uma repolitização da legitimidade. 3 ed. São Paulo: Malheiros Editores, 2008.

CADERNO DE DIRETRIZES - CONSULTA POPULAR 2016-2017. Disponível em: <http://www.sdr.rs.gov.br/upload/20170126101042caderno_de_diretrizes_ versao_completa2.pdf>. Acesso em: 01 fev. 2017.

COMPOSIÇÃO DO CODEMI. Disponível em: < https://leismunicipais.com.br/ a1/rs/i/ijui/decreto/2014/543/5438/decreto-n-5438-2014-aprova-o-regimentointerno-do-conselho-de-desenvolvimento-do-municipio-de-ijui-codemi-revogadecreto-que-menciona-e-da-outras-providencias>. Acesso em: 26 abr. 2017.

CÓRDOBA, Manuel B. F. de. El interés general en la filosofía política. Un concepto ético y normativo necesario para la planificación territorial. Boletín de la Asociación de Geógrafos Españoles, n. 53, 2010. Disponível em: < http://www.boletinage. com/articulos/53/06-Benavent\%20121-146.pdf>. Acesso em: 12 abr. 2017.

DALLABRIDA, Valdir R. Descentralização político-administrativa no Brasil: possibilidades de avanços rumo a uma prática de democracia deliberativa. In: SEMINÁRIO DE DESENVOLVIMENTO REGIONAL, ESTADO E SOCIEDADE, 1. Rio de Janeiro, 2012. Anais... Rio de Janeiro: ANPUR, 2012. Disponível em: <http://www.anpur.org.br/revista/rbeur/index.php/sedres/ article/view/3917/3828>. Acesso em: 22 mar. 2017.

DECRETO 35.764 que regulamenta a Lei no 10.283, de 17 de outubro de 1994, que criou os Coredes. Disponível em: <http:/ /www.al.rs.gov.br/Legis/M010/M0100099. 
ASP?Hid_Tipo=TEXTO\&Hid_TodasNormas $=12439 \&$ hTexto $=\& H i d$ IDNorma=12439>. Acesso em: 14 abr. 2017.

DECRETO 1.798, de 04 de Abril de 1994. Aprovação do regimento interno. Disponível em: <http://camara-municipal-de-ijui.jusbrasil.com.br/ legislacao/920464/decreto-1798-94>. Acesso em: 30 abr. 2017.

ETGES, Virginia Elisabeta. A região no contexto da globalização: o caso do Vale do Rio Pardo. In: VOGT, Olgário; SILVEIRA, Rogério. Vale do Rio Pardo: (re) conhecendo a região. Santa Cruz do Sul: Edunisc. 2001.

FERRÃO, João. Governança e Ordenamento do Território. Reflexões para uma Governança Territorial Eficiente, Justa e Democrática. Prospectiva e Planeamento, v. 17, p. 129-139, 2010. Disponível em: <https://economiadoterritorio.files. wordpress.com/2014/11/governanca-e-ordenamento-do-territc3b3rio.pdf $>$. Acesso em: 31 jun. 2017.

HABERMAS, Jürgen. Teoria de la acción comunicativa. Madrid: Taurus, 1987. v. 1

IBGE. Censo Demográfico. Brasília: Gov. Federal, 2010. Disponível em: Disponível em: $\quad<$ http://www.censo2010.ibge.gov.br/sinopse/index.php?uf=43\&dados $=1>$. Acesso em: 06 maio 2017.

LEI n 10.283 , de 17 de outubro de 1994. Dispõe sobre a criação, estruturação e funcionamento dos Conselhos Regionais de Desenvolvimento. Disponível em: <http://www.al.rs.gov.br/Legis/M010/M0100099.ASP?Hid_ Tipo $=$ TEXTO\&Hid_TodasNormas $=12666 \&$ hTexto $=\& H i d \_I D N o r m a=12666>$. Acesso em: 01 fev. 2017.

LEI no 11.179, de 25 de junho de 1998. Dispõe sobre a consulta direta à população. Disponível em: <http://www.al.rs.gov.br/FileRepository/repLegisComp/Lei\%20 n\%C2\%BA\%2011.179.pdf>. Acesso em: 10 abr. 2017.

LEI $\mathrm{n}^{\circ}$ 2.743, de março de 1992. Da criação do CODEMI. Disponível em: <https://leismunicipais.com.br/a1/rs/i/ijui/lei-ordinaria/1992/275/2743/leiordinaria-n-2743-1992-cria-o-conselho-de-desenvolvimento-do-municipio-de-ijui-eda-outras-providencias?q=2743>. Acesso em: 30 abr. 2017.

LEI no 5.438, de 12 de dezembro de 2013. Prevê a atualização do regimento interno do Codemi. Disponível em: < https://leismunicipais.com.br/a1/rs/i/ijui/ decreto/2014/543/5438/decreto-n-5438-2014-aprova-o-regimento-interno-doconselho-de-desenvolvimento-do-municipio-de-ijui-codemi-revoga-decreto-que- 
menciona-e-da-outras-providencias >. Acesso em: 30 abr. 2017.

MARQUETTTI, Adalmir. Participação e redistribuição: o Orçamento Participativo em Porto Alegre. In: AVRITZER, Leonardo; NAVARRO, Zander (Org.). A inovação democrática no Brasil. São Paulo: Cortez, 2003. p. 129-156.

PIRES, Roberto; LOPEZ, Félix. Instituições participativas e políticas públicas no Brasil: características e evolução nas últimas duas décadas. In: Brasil em desenvolvimento 2010: Estado, planejamento e políticas públicas. Brasília: IPEA, 2010. p. 565-585. Disponível em: < http://www.ipea.gov.br/participacao/images/ instituies $\% 20$ participativas $\% 20$ nas $\% 20$ ultimas $\% 20$ dcadas.pdf $>$. Acesso em: 23 abr. 2017.

PLANO DIRETOR DE IJUÍ. Disponível em: <http://www.ijui.rs.gov.br/ paginapref/plano_diretor>. Acesso em: 10 maio 2017.

RAWLS, John. The law of people: with, the idea of public reason revisited. Harvard University Press. Cambridge, 2001.

ROUSSEAU, Jean J. Do contrato social; Ensaio sobre a origem das línguas; Discurso sobre a origem e os fundamentos da desigualdade entre os homens; Discurso sobre as ciências e as artes. 3. ed. São Paulo: Abril Cultural, 1983.

SÁNCHEZ, Félix. Orçamento participativo: teoria e prática. São Paulo: Cortez, 2002.

SANTOS, Milton. Técnica, espaço, tempo: globalização e meio técnico-científico informacional. 3. ed. São Paulo: Hucitec, 1997.

SILVEIRA, Rogério L. da Silva; ALLEBRADNT, Sérgio L.; CAMPOS, Heleniza À. O Planejamento e o Desenvolvimento Regional no Rio Grande do Sul: Políticas Estaduais, Processos e Experiências Regionais. In: FELIPPI, Ângela C. T.; SILVEIRA, Rogério L. da Silva; ALLEBRANDT, Sérgio L. (Org.). Observando o planejamento regional no Rio Grande do Sul: uma análise da experiência recente dos Conselhos Regionais de Desenvolvimento (COREDEs). Santa Cruz do Sul: EDUNISC, 2015. p. 49-75. Disponível em: < http://www.unisc.br/portal/upload/ com_editora_livro/ebook_coredes_final.pdf>. Acesso em: 24 abr. 2017.

VITALE, Denise. Democracia direta e poder local: a experiência brasileira do Orçamento Participativo. In: COELHO, Vera S. P.; NOBRE, Marcos (Org.). Participação e deliberação. São Paulo: Ed 34, 2004. p. 239-254. 
